\title{
Tyropeptins, proteasome inhibitors produced by Kitasatospora sp. MK993-dF2
}

\author{
Isao Momose ${ }^{1}$ and Takumi Watanabe ${ }^{2}$ \\ Tyropeptins are new proteasome inhibitors isolated from the culture broth of Kitasatospora sp. MK993-dF2. Tyropeptins \\ permeate cell membranes, inhibit intracellular proteasomes and reduce the degradation of ubiquitinated proteins in mammalian \\ cells. We performed structure-based drug design and structure-activity relationship studies on tyropeptin derivatives to obtain \\ valuable information of derivatives. Among the synthesized tyropeptin derivatives, some boronic acid derivatives exhibited potent \\ antitumor effects against human multiple myeloma. In this review, we summarize the discovery of tyropeptins and the
} development of tyropeptin derivatives.

The Journal of Antibiotics (2017) 70, 542-550; doi:10.1038/ja.2017.9; published online 15 February 2017

\section{INTRODUCTION}

The ubiquitin-proteasome system is the major intracellular protein degradation system in eukaryotic cells. This system selectively degrades short-lived regulatory proteins involved in the homeostatic control of cells as well as abnormal proteins with misfolded structures. ${ }^{1}$ The conjugation of ubiquitin to target proteins serves as a signal for degradation by the proteasome. Protein destruction is initiated by covalent attachment of the ubiquitin chain (a chain comprising more than four ubiquitin monomers) through the sequential actions of a network of proteins, including E1 (ubiquitin-activating), E2 (ubiquitin-conjugating) and E3 (ubiquitin-ligating) enzymes, and then the polyubiquitinated proteins are degraded by the $26 \mathrm{~S}$ proteasome. ${ }^{2,3}$ The $26 \mathrm{~S}$ proteasome is an unusually large multienzyme and an ATP-dependent proteolytic complex that comprises a hollow cylindrical 20S proteolytic core (20S proteasome) and one or two $19 \mathrm{~S}$ regulatory particles (Figure 1). ${ }^{4-6}$ Polyubiquitinated proteins are recognized by the $19 \mathrm{~S}$ regulatory particle, are fed into the $20 \mathrm{~S}$ proteasome core and are cleaved into small peptides. The $20 \mathrm{~S}$ proteasome comprises 28 protein subunits and is organized as two outer $\alpha$-rings and two inner $\beta$-rings in an axial stack $(\alpha \beta \beta \alpha)$. Each ring comprises seven distinct subunits, forming an $\alpha_{1-7} \beta_{1-7} \beta_{1-7} \alpha_{1-7}$ structure. The $20 \mathrm{~S}$ proteasome possesses three distinct protease activities, caspase-like/peptidyl-glutamyl peptide hydrolyzing, trypsinlike and chymotrypsin-like activities, which are mediated by the active sites of $\beta 1, \beta 2$ and $\beta 5$ subunits, respectively. All of the active sites contain an $\mathrm{N}$-terminal threonine, which acts as the catalytic nucleophile in peptide bond hydrolysis. ${ }^{7}$

The proteasome influences tumor growth by controlling the degradation of regulatory proteins. For example, the proteasome degrades proteins associated with cell cycle regulation, such as cyclins, cyclin-dependent kinase inhibitors (for example, p21 and p27), tumor suppressors (for example, p53) and nuclear factor (NF)- $\mathrm{\kappa B}$ inhibitors (for example, IкB- $\alpha$ ). ${ }^{8-11}$ In fact, many effective proteasome inhibitors that stabilize these regulatory proteins have been developed ${ }^{12-16}$ and induce cell cycle arrest, endoplasmic reticulum stress and apoptosis, thereby inhibiting tumor growth. ${ }^{17,18}$ This makes the proteasome an attractive target in cancer therapy, and proteasome inhibitors are promising candidate antitumor agents. ${ }^{19,20}$ Several proteasome inhibitors were discovered from natural products. Lactacystin, discovered by Professor S Omura, was originally isolated from the culture broth of Streptomyces sp. as a novel inducer of neurite outgrowth in neuroblastoma cells. ${ }^{21,22}$ Extensive studies on its mechanism of action revealed that lactacystin acts as a proteasome inhibitor. ${ }^{23}$ Furthermore, lactacystin is nonenzymatically hydrolyzed to the active lactacystin analog, clasto-lactacystin $\beta$-lactone, designated omuralide. ${ }^{24-26}$

Natural microbial metabolites often have therapeutic activities that can improve general health and can be used to treat diseases. They are a hopeful resource in drug discovery because of their considerable chemical diversity. Umezawa and Aoyagi have isolated various kinds of protease inhibitors, such as leupeptin, antipain, pepstatin and chymostatin, from microbial metabolites. ${ }^{27,28}$ We have also screened new proteasome (multi-protease complex) inhibitors derived from microbial metabolites and have isolated new proteasome inhibitors called tyropeptins from the culture broth of actinomycetes. In this review, we report the discovery of tyropeptins and the development of tyropeptin derivatives.

\section{DISCOVERY OF TYROPEPTINS}

In 2000, tyropeptins were discovered in the culture broth of the soil Actinomycete strain MK993-dF2 (Figure 2a). ${ }^{29}$ Taxonomic studies indicated that the tyropeptin-producing strain MK993-dF2 is closely related to members of the genus Kitasatospora, ${ }^{30,31}$ which was isolated

${ }^{1}$ Institute of Microbial Chemistry (BIKAKEN), Shizuoka, Japan and ${ }^{2}$ Institute of Microbial Chemistry (BIKAKEN), Tokyo, Japan

Correspondence: Dr I Momose, Institute of Microbial Chemistry (BIKAKEN), Numazu Branch, 18-24 Miyamoto, Numazu-shi, Shizuoka 410-0301, Japan.

E-mail: imomose@bikaken.or.jp

This paper is dedicated to Professor Dr Satoshi Ōmura for his Nobel Prize in Physiology or Medicine, 2015.

Received 17 October 2016; revised 9 December 2016; accepted 13 December 2016; published online 15 February 2017 


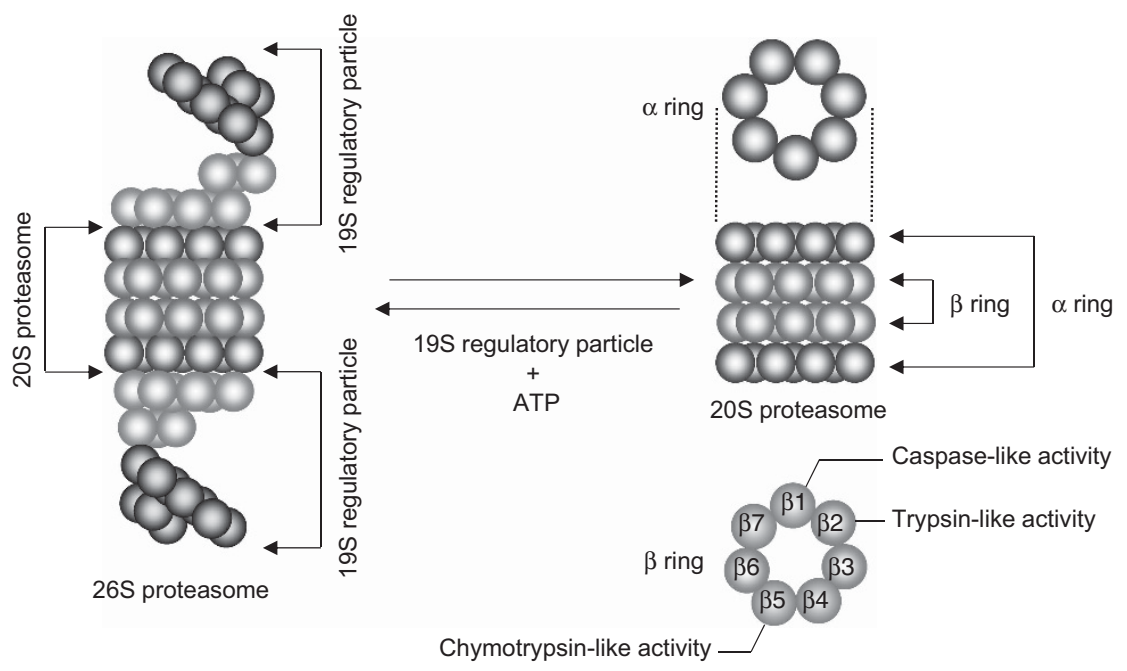

Figure 1 Schematic model of the proteasome.

a

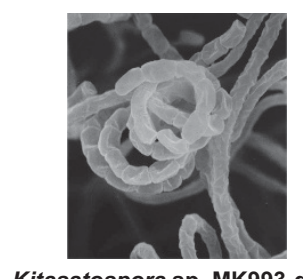

Kitasatospora sp. MK993-dF2 b

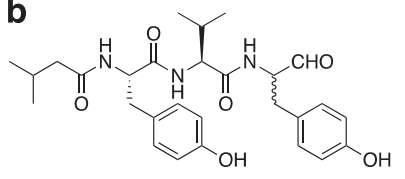

Tyropeptin A

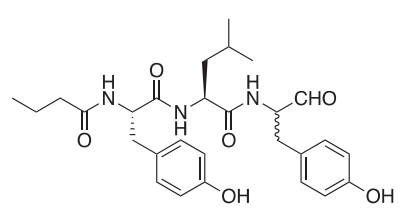

Tyropeptin B

C

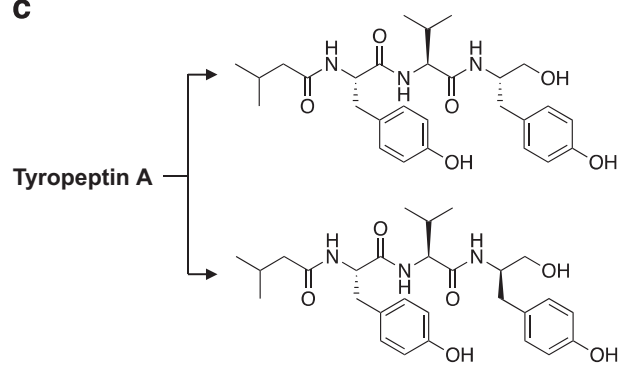

Figure 2 Tyropeptins A and B. (a) Scanning electron micrograph of Kitasatospora sp. MK993-dF2. (b) Structures of tyropeptins A and B. (c) Alcohol derivatives of tyropeptin A.

by Professor Omura as a setamycin (bafilomysin B1)-producing bacterium. Kitasatospora setae NBRC $14216^{\mathrm{T}}$, a member of the genus Kitasatospora, is predicted to have 24 genes or gene clusters that are involved in the biosynthesis of secondary metabolites. ${ }^{32}$ Therefore, Kitasatospora is well recognized as an important genus in the study of secondary metabolites. Although the genus Kitasatospora is morphologically very similar to the genus Streptomyces, they are distinguishable on the basis of cell wall composition and the $16 \mathrm{~S}$ rDNA sequence. Because the strain MK993-dF2 showed the taxonomic characteristics of the genus Kitasatospora, it was classified as a member of that genus, and the strain was designated as Kitasatospora sp. MK993-dF2.

Tyropeptins A and B were purified from the culture broth of Kitasatospora sp. MK993-dF2 using various types of column chromatography (Figure 2b). Structures of the tyropeptins were determined

Table 1 Inhibition of 20 S proteasome by tyropeptins

\begin{tabular}{lccc}
\hline & \multicolumn{3}{c}{$I_{50}(\mu \mathrm{M})$} \\
\cline { 2 - 4 } Compounds & $\begin{array}{c}\text { Chymotrypsin-like } \\
\text { activity }\end{array}$ & $\begin{array}{c}\text { Caspase-like } \\
\text { activity }\end{array}$ & $\begin{array}{c}\text { Tyrpsin-like } \\
\text { activity }\end{array}$ \\
\hline Tyropeptin A & 0.20 & $>100$ & 2.9 \\
Tyropeptin B & 0.39 & $>100$ & 7.8 \\
MG132 & 0.11 & 4.2 & 4.2 \\
\hline
\end{tabular}

Abbreviation: $\mathrm{I}_{50}$, half maximal inhibitory concentration.

$20 \mathrm{~S}$ proteasome was prepared from the mouse liver.

using spectroscopic analysis and chemical conversion. ${ }^{33}$ Tyropeptins give positive color reactions with a Rydon HN and Smith PWG reagent on thin-layer chromatography, indicating the presence of peptide bonds. ${ }^{34}$ Moreover, tyropeptins yield positive color reactions with a 2,4-dinitrophenylhydrazine reagent on thin-layer chromatography, and the infrared spectra of tyropeptins show an absorption peak at $1730 \mathrm{~cm}^{-1}$, indicating the presence of an aldehyde group. The ${ }^{1} \mathrm{H}$ and ${ }^{13} \mathrm{C}$ nuclear magnetic resonance spectra of tyropeptins are considerably complicated owing to epimerization at the asymmetric center. Taken together, these characteristics indicate that tyropeptins are peptide aldehyde inhibitors. Therefore, we converted the tyropeptins to their alcohol derivatives to obtain assignable nuclear magnetic resonance spectra (Figure 2c). Configuration of the amino-acid residues was determined using liquid chromatography/mass spectroscopy analysis of the free amino acids obtained from acid hydrolysis of the tyropeptin-alcohol derivatives. Furthermore, tyropeptins were synthesized to confirm their structures. The spectroscopic data and proteasome-inhibitory activities of synthetic tyropeptins are identical to those of natural tyropeptins. Therefore, the structures of tyropeptins $\mathrm{A}$ and $\mathrm{B}$ were concluded to be isovaleryl-L-tyrosyl- L -valyl-DL-tyrosinal and $n$-butyryl-L-tyrosyl-L-leucyl-DL-tyrosinal, respectively.

As we mentioned earlier, the $20 \mathrm{~S}$ proteasome has three distinct proteolytic activities, chymotrypsin-like, trypsin-like and caspase-like. Its chymotrypsin-like activity preferentially cleaves peptide amide bonds after large hydrophobic amino-acid residues (for example, tyrosine, tryptophan and phenylalanine). The trypsin-like activity preferentially cuts peptide bonds after basic amino acids (for example, lysine and arginine), and the caspase-like activity is traditionally 
a

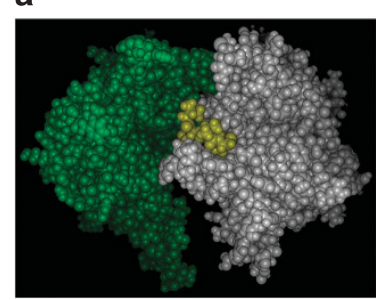

b

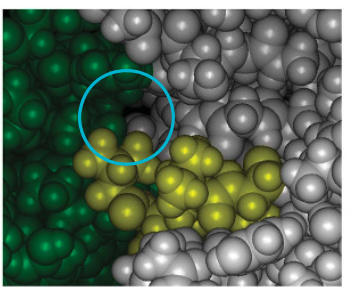

d

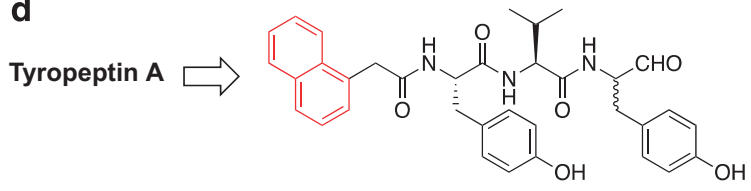

TP-104
C

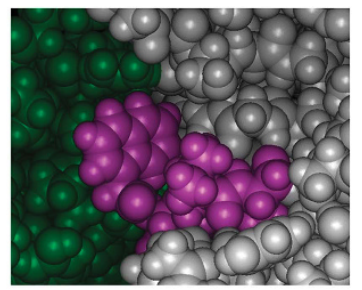

Figure 3 Binding model of tyropeptin A bound to the site responsible for the chymotrypsin-like activity of $20 \mathrm{~S}$ proteasome. (a) Overview of the binding model. Subunit $\beta 5$, gray; subunit $\beta 6$, green; and tyropeptin A, yellow. (b) Magnification of a part in a. (c) Binding model of TP-104 bound to the $\beta 5 / \beta 6$ site. TP-104, purple. (d) Structure of TP-104.

Table 2 Biological activities of tyropeptin derivatives<smiles>[R]CC(=O)N[C@@H](Cc1ccc(O[R2])cc1)C(=O)N[C@H](C(=O)N[C@H](C=O)Cc1ccc(O[R16])cc1)C(C)C</smiles>

$I_{50}(\mu \mathrm{M})$

20 proteasome

\begin{tabular}{|c|c|c|c|c|c|c|c|}
\hline Compound & $R_{1}$ & $R_{2}$ & $R_{3}$ & Chymotrypsin-like activity & Caspase-like activity & Trypsin-like activity & Cytotoxicity RPMI8226 cells \\
\hline Tyropeptin A & $\mathrm{CH}\left(\mathrm{CH}_{3}\right)_{2}$ & $\mathrm{H}$ & $\mathrm{H}$ & 0.14 & 68 & 5 & 4.1 \\
\hline TP-101 & $\mathrm{C}_{6} \mathrm{H}_{11}$ & $\mathrm{H}$ & H & 0.033 & 17 & 3 & 0.27 \\
\hline TP-102 & $\mathrm{C}_{6} \mathrm{H}_{5}$ & H & H & 0.027 & 16 & 2 & 1.2 \\
\hline TP-104 & 1-Naphthyl & $\mathrm{H}$ & $\mathrm{H}$ & 0.007 & 4.9 & 1.2 & 0.20 \\
\hline TP-105 & $\mathrm{CH}_{2}\left(\mathrm{CH}_{2}\right)_{3} \mathrm{CH}_{3}$ & H & H & 0.037 & 20 & 2 & 0.33 \\
\hline TP-106 & $\mathrm{CH}\left(\mathrm{CH}_{3}\right)_{2}$ & $\mathrm{H}$ & $\mathrm{CH}_{3}$ & 0.19 & 21 & 21 & 0.68 \\
\hline TP-109 & 1-Naphthyl & $\mathrm{CH}_{3}$ & $\mathrm{H}$ & 0.020 & 31 & 6 & 0.021 \\
\hline TP-110 & 1-Naphthyl & $\mathrm{CH}_{3}$ & $\mathrm{CH}_{3}$ & 0.027 & $>100$ & $>100$ & 0.012 \\
\hline TP-111 & $\mathrm{N}\left(\mathrm{CH}_{3}\right)_{2}$ & $\mathrm{H}$ & H & 1.2 & $>100$ & 7.8 & $>20$ \\
\hline MG132 & & & & 0.068 & 1.4 & 4.5 & 1.5 \\
\hline
\end{tabular}

Abbreviation: $\mathrm{IC}_{50}$, half maximal inhibitory concentration.

$20 \mathrm{~S}$ proteasome was prepared from the mouse liver.

termed 'peptidyl-glutamyl peptide hydrolase activity' because it preferentially splits peptide bonds after acidic residues. The peptidylglutamyl peptide hydrolase activity involves cleaving after aspartic acid residues faster than after glutamic acid residues, suggesting that this activity is 'caspase-like'. The structures of tyropeptins are similar to those of substrates for the chymotrypsin-like activity, thus tyropeptins A and B potently inhibit the chymotrypsin-like activity of $20 \mathrm{~S}$ proteasome with an half maximal inhibitory concentration $\left(\mathrm{IC}_{50}\right)$ values of 0.2 and $0.39 \mu \mathrm{M}$, respectively (Table 1). Lineweaver-Burk plots indicate that tyropeptins competitively inhibit the chymotrypsinlike activity. Proteasome inhibitor MG132, benzyloxycarbonyl-leucylleucyl-leucinal, ${ }^{35}$ inhibits the three proteolytic activities of $20 \mathrm{~S}$ proteasome, but tyropeptins cannot inhibit its trypsin-like activity.

To clarify whether tyropeptin A permeates through cell membranes and inhibits the intracellular proteasome activity, we investigated the effects of tyropeptin A on rat pheochromocytoma PC12 cells. 
Tyropeptin A treatment clearly reduced proteasome activity in PC12 cells and increased the accumulation of ubiquitinated proteins as endogenous substrates for the proteasome in a dose-dependent manner. ${ }^{36}$ Furthermore, tyropeptin A induced neurite outgrowth on PC12 cells, similar to the nerve growth factor. It should be noted that proteasome inhibitors such as MG132 and lactacystin induce neurite outgrowth in PC12 cells as well. ${ }^{35,37}$ These observations indicate that tyropeptin A permeates cell membranes and inhibits the intracellular proteasome activity of $\mathrm{PC} 12$ cells.

\section{DESIGN OF TYROPEPTIN DERIVATIVES}

Although tyropeptin A is a potent proteasome inhibitor, its inhibitory potency against the chymotrypsin-like activity of $20 \mathrm{~S}$ proteasome is weaker than that of MG132 (Table 1). To enhance the inhibitory potency of tyropeptin A, we performed a structure-based drug design. The crystal structure of the human $20 \mathrm{~S}$ proteasome had not yet been determined at that time; however, the crystal structure of the yeast (Saccharomyces cerevisiae) and mammalian (bovine and mouse) 20S proteasomes had been known. ${ }^{38-41}$ The binding site responsible for the chymotrypsin-like activity of the $20 \mathrm{~S}$ proteasome is formed by the association of $\beta 5$ and $\beta 6$ subunits, ${ }^{40}$ and the amino-acid sequences of the $\beta 5$ and $\beta 6$ subunits of the bovine 20S proteasome show $100 \%$ identity with those of the human $20 \mathrm{~S}$ proteasome. Therefore, we constructed a structural model of tyropeptin A bound to the $\beta 5 / \beta 6$ site conferring the chymotrypsin-like activity of bovine $20 \mathrm{~S}$ proteasome to obtain valuable steric information for derivatization (Figure 3a). ${ }^{42}$ The aldehyde group of tyropeptin A might form a hemiacetal adduct with the catalytic Thr 1 residue of the $\beta 5$ subunit. Moreover, the tyrosinal, valine and tyrosine residues of tyropeptin A may mimic the role of the P1, P2 and P3 amino acids of the binding sites for the natural substrates of the proteasome, respectively. We investigated the most favorable orientation of tyropeptin $A$ in the $\beta 5 / \beta 6$-binding site model and found that tyropeptin A fits well into the $\beta 5 / \beta 6$ site (Figure $3 \mathrm{~b}$ ). This binding model suggested the presence of an open space near the $N$-terminal of tyropeptin A. We speculated that a compound capable of filling the open space would exhibit enhanced inhibitory activity against the chymotrypsin-like activity of the $20 \mathrm{~S}$ proteasome. Therefore, we designed tyropeptin A derivatives having a bulky $N$-terminal moiety and synthesized several tyropeptin A derivatives with modifications at the $N$-terminal moiety (Table 2$).{ }^{43}$ Replacement of the isopropyl group of tyropeptin A with a cyclohexyl group (TP-101) resulted in a fourfold enhancement of its inhibitory potency for chymotrypsin-like activity compared with original tyropeptin A. Aromatization of the cyclohexyl group (TP-102) resulted in a fivefold enhancement of its inhibitory potency for chymotrypsin-like activity compared with tyropeptin A. Furthermore, TP-103 having two aromatic rings (that is, a 2-naphthyl group) showed a 10-fold increase in the inhibitory potency for chymotrypsin-like activity. TP-104 having a 1-naphthyl group exhibited an inhibitory activity stronger than TP-103 having a 2-naphthyl group. TP-105 having a pentyl group, however, showed a lower inhibitory activity than TP-104. Among them, the most potent compound for the chymotrypsin-like activity was the 1-naphthyl derivative, TP-104, which exhibited a 20-fold greater inhibitory potency compared with the original tyropeptin A. As shown in Figure 3c, TP-104 complemented the shape of the open space in the vicinity of the $N$-terminal of tyropeptin A and formed new $\mathrm{CH} / \pi$ interactions with the $\beta 5 / \beta 6$ site of the $20 \mathrm{~S}$ proteasome (Figure $3 \mathrm{~d}$ ). Therefore, the very high affinity of TP-104 to the $\beta 5 / \beta 6$ site increased the inhibitory potency for the chymotrypsinlike activity of $20 \mathrm{~S}$ proteasome relative to tyropeptin A. Taken together, our binding model of the bovine $20 \mathrm{~S}$ proteasome allowed for suitable design of a potent inhibitor of the $20 \mathrm{~S}$ proteasome.

TP-104 inhibited the chymotrypsin-like activity of $20 \mathrm{~S}$ proteasome with an $\mathrm{IC}_{50}$ value of $0.007 \mu \mathrm{M}$ stronger than MG132 with an $\mathrm{IC}_{50}$ value of $0.068 \mu \mathrm{M}$. Encouraged by the excellent proteasome inhibitory activity of TP-104, we further synthesized various tyropeptin A derivatives. Tyropeptin A derivative, TP-110, inhibited the chymotrypsin-like activity of $20 \mathrm{~S}$ proteasome with an $\mathrm{IC}_{50}$ value of $0.027 \mu \mathrm{M}$ but did not inhibit the trypsin- and caspase-like activities at a concentration of $100 \mu \mathrm{M}$, indicating an enhanced specificity for the chymotrypsin-like activity. The active site of trypsin-like activity is formed by the association of the $\beta 2$ and the $\beta 3$ subunits and is narrower than that needed for the chymotrypsin-like activity. ${ }^{39}$ Therefore, TP-110 may not optimally fit into the $\beta 2 / \beta 3$ site, which makes it a potent and selective inhibitor of the chymotrypsin-like activity of $20 \mathrm{~S}$ proteasome. Furthermore, TP-110 inhibited the growth of human multiple myeloma RPMI8226 cells with an $\mathrm{IC}_{50}$ value of $0.012 \mu \mathrm{M}$ and showed more potent cytotoxicity against various human cancer cells than TP-104. ${ }^{43}$

We then investigated the effects of TP-110 on human cancer cells. ${ }^{44}$ TP-110 strongly inhibited the growth of human prostate cancer PC-3 cells in vitro. It increased the protein levels of p21 and p27, which are negative regulators of cell cycle progression and increased the number of cells in the G2/M phase. Furthermore, TP-110 induced apoptosis along with chromatin condensation and DNA fragmentation, and the TP-110-induced apoptosis appeared to be associated with caspase activation. TP-110 also induced apoptosis in human multiple myeloma RPMI8226 cells, ${ }^{45}$ in addition to enhancing the release of cytochrome $c$ from the mitochondria into the cytosol, and reduced the levels of cIAP-1 and XIAP, which are intrinsic inhibitors of apoptosis proteins and bind to inhibit caspases. Consequently, caspase- 8 and -3 were activated by TP-110, resulting in the cleavage of poly (ADP-ribose) polymerase, a main cleavage target of caspase-3. As mentioned earlier, TP-110 exhibits interesting biological activity but no antitumor activity in vivo. Moreover, TP-110 was effluxed by P-glycoprotein (MDR1), a multidrug efflux transporter. ${ }^{46}$ Therefore, we synthesized more effective TP-110 derivatives.

\section{DEVELOPMENT OF TYROPEPTIN-BORONIC ACID DERIVATIVES}

Bortezomib (formerly known as PS-341) was the first therapeutic proteasome inhibitor developed to treat cancer (Figure 4a). It potently inhibits the chymotrypsin-like activity of the $20 \mathrm{~S}$ proteasome and suppresses the growth of various cancer cells and xenograft tumors in animal models. ${ }^{47,48}$ Bortezomib shows particular efficacy against multiple myeloma. Because multiple myeloma cells produce large amounts of proteins, including immunoglobulins, they impose an unusually high burden on the proteasome. Therefore, extensive immunoglobulin production increases their sensitivity to proteasome inhibition, ${ }^{49}$ and the unfolded protein response can be easily induced by proteasome inhibition. ${ }^{50}$ The efficacy of bortezomib in treating multiple myeloma was subsequently confirmed by a phase I through phase III clinical trials. ${ }^{51-54}$ Bortezomib was approved as a first-inclass proteasome inhibitor for third-line treatment of relapsed and refractory multiple myeloma by the United States Food and Drug Administration in 2003, and it was approved as first-line treatment for newly diagnosed multiple myeloma in 2008. ${ }^{55-57}$ Furthermore, bortezomib was approved for the treatment of relapsed and refractory mantle cell lymphoma in $2006 .^{58}$

Bortezomib has a boronic acid structure at its C-terminus (P1); it forms covalent bonds with nucleophilic substituents such as the hydroxy group in the active site, which dissociate slowly under 
physiological conditions resulting in enhanced antiproteasome activity compared with the aldehyde congeners. Inspired by the concept of the molecular design of bortezomib, we synthesized a TP-110-boronic acid derivative (Figure 4b). To synthesize the TP-110-boronic acid derivative, the boronic acid congener of the O-Me-tyrosine was prepared according to the procedure described by Matteson and

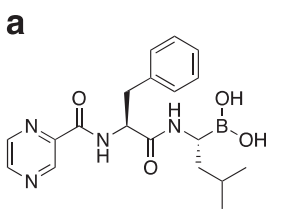

Bortezomib

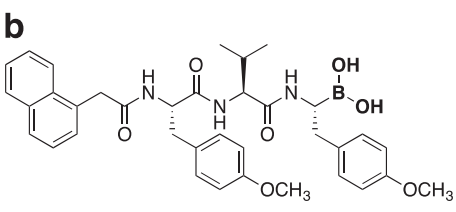

TP-110-boronic acid derivative
Figure 4 Structure of bortezomib and TP-110-boronic acid derivative. (a) Bortezomib. (b) TP-110-boronic acid derivative.

Table 3 Inhibition of 20 S proteasome by the TP-110-boronic acid derivative

\begin{tabular}{lccc}
\hline & \multicolumn{3}{c}{$I C_{50}(\mu \mathrm{m})$} \\
\cline { 2 - 4 } Compounds & $\begin{array}{c}\text { Chymotrypsin-like } \\
\text { activity }\end{array}$ & $\begin{array}{c}\text { Caspase-like } \\
\text { activity }\end{array}$ & $\begin{array}{c}\text { Tyrpsin-like } \\
\text { activity }\end{array}$ \\
\hline TP-110-boronic acid & 0.0063 & $>40$ & 5.6 \\
TP-110 & 0.083 & $>40$ & $>40$ \\
Bortezomib & 0.024 & 0.73 & $>40$ \\
\hline
\end{tabular}

Abbreviation: $\mathrm{IC}_{50}$, half maximal inhibitory concentration. $20 S$ proteasome was prepared from human erythrocytes. coworkers. ${ }^{59,60}$ The resulting aminoboronic acid was condensed with a dipeptide, 1-naphthylacetyl-Tyr $(\mathrm{Me})-\mathrm{Val}-\mathrm{OH}$, to give the TP-110-boronic acid derivative. ${ }^{61}$ The TP-110-boronic acid derivative inhibited chymotrypsin-like activity with an $\mathrm{IC}_{50}$ value of $0.0063 \mu \mathrm{M}$, which is more potent than the aldehyde congener TP-110 with an $\mathrm{IC}_{50}$ value of $0.083 \mu \mathrm{M}$ (Table 3). Substitution of the aldehyde group in TP-110 with boronic acid resulted in more than a 10 -fold increase in the inhibitory potency against the chymotrypsin-like activity. The TP-110-boronic acid derivative also showed more potent inhibitory effects than bortezomib with an $\mathrm{IC}_{50}$ value of $0.024 \mu \mathrm{M}$.

Upon validation of the concept of boronic acid derivatives of tyropeptin, we performed structure-activity relationship studies focused mainly on structural modifications of the $N$-terminal acyl functionality, together with preliminary investigation of P1 and P2 variants (Figure 5). ${ }^{62}$ We envisioned that a pyrazyl moiety of bortezomib would enhance its biological activity and introduced a variety of aromatic rings, including $N$-heterocycles, at the $N$-terminus. Table 4 shows the inhibitory potency of tyropeptin-boronic acid derivatives against $20 \mathrm{~S}$ proteasome and cytotoxicity toward RPMI8226 cells. Except for AS-9, quinolyl and isoquinolyl derivatives (from AS-7 to AS-13) inhibited the chymotrypsin-like activity of 20 s proteasome more effectively than the pyridyl and pyrazyl congeners (from AS-14 to AS-17). Among the synthesized derivatives, AS-06 with a phenoxyphenyl moiety at the $N$-terminal acyl moiety exhibited the most potent inhibitory activity with an $\mathrm{IC}_{50}$ value of $0.0041 \mu \mathrm{M}$ against the chymotrypsin-like activity; the potency was almost ninefold higher than bortezomib with an $\mathrm{IC}_{50}$ value of $0.039 \mu \mathrm{m}$. Unfortunately, however, AS-06 showed only weak cytotoxicity against human multiple myeloma RPMI8226 cells.

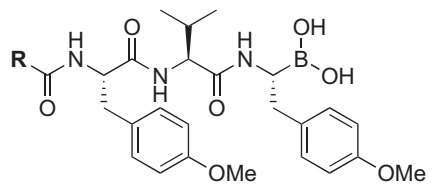

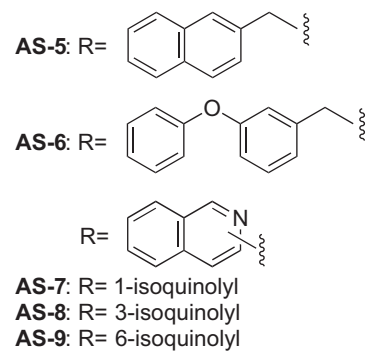

AS-8: $R=3$-isoquinoly AS-9: $R=6$-isoquinoly
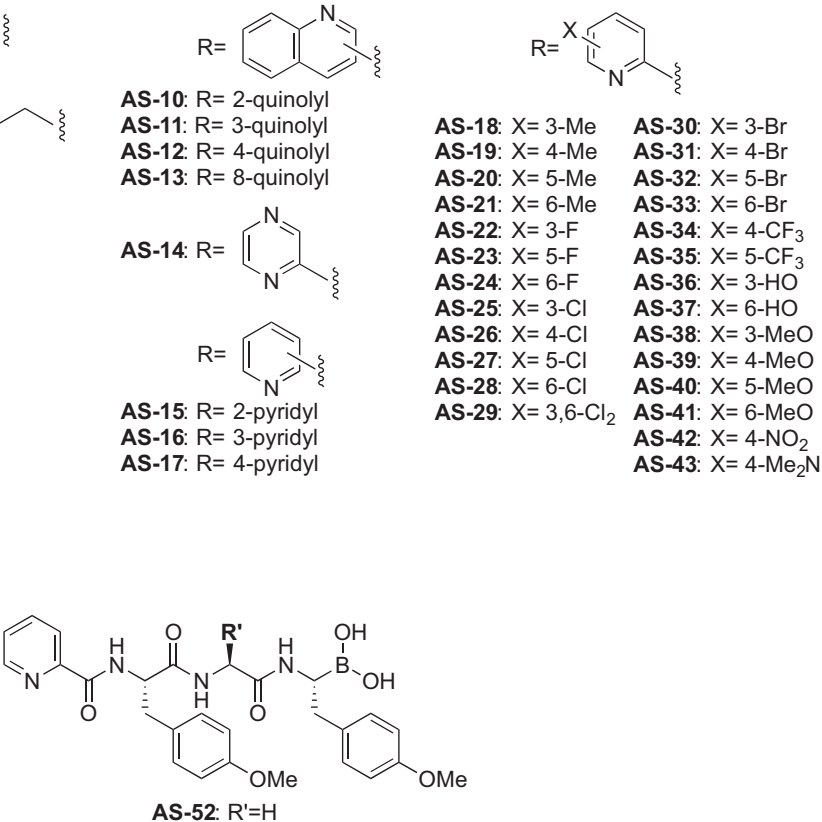

AS-53: $\mathrm{R}^{\prime}=\mathrm{Me}$

Figure 5 Structure of tyropeptin-boronic acid derivatives. 
Table 4 Biological activities of tyropeptin-boronic acid derivatives

\begin{tabular}{|c|c|c|c|c|}
\hline \multirow[b]{3}{*}{ Compounds } & \multicolumn{4}{|c|}{$1 C_{50}(\mu \mathrm{M})$} \\
\hline & \multicolumn{3}{|c|}{20 s proteasome } & \multirow[b]{2}{*}{$\begin{array}{c}\text { Cytotoxicity } \\
\text { RPMI8226 cells }\end{array}$} \\
\hline & $\begin{array}{c}\text { Chymotrypsin-like } \\
\text { activity }\end{array}$ & $\begin{array}{c}\text { Caspase-like } \\
\text { activity }\end{array}$ & $\begin{array}{l}\text { Trypsin-like } \\
\text { activity }\end{array}$ & \\
\hline AS-5 & 0.022 & 39 & 12 & 0.17 \\
\hline AS-6 & 0.0041 & 29 & 1.1 & 0.19 \\
\hline AS-7 & 0.041 & 19 & 10 & 0.034 \\
\hline AS-8 & 0.059 & 11 & 9.0 & 0.093 \\
\hline AS-9 & 0.38 & $>40$ & $>40$ & 0.26 \\
\hline AS-10 & 0.10 & 16 & 5.4 & 0.073 \\
\hline AS-11 & 0.056 & 32 & 10 & 0.054 \\
\hline AS-12 & 0.049 & 24 & 8.6 & 0.049 \\
\hline AS-13 & 0.093 & 16 & 18 & 0.056 \\
\hline AS-14 & 0.24 & 33 & 19 & 0.017 \\
\hline AS-15 & 0.23 & 23 & 40 & 0.013 \\
\hline AS-16 & 0.50 & $>40$ & $>40$ & 0.87 \\
\hline AS-17 & 2.3 & $>40$ & $>40$ & 0.87 \\
\hline AS-18 & 0.085 & $>40$ & 20 & 0.014 \\
\hline AS-19 & 0.14 & 30 & 20 & 0.014 \\
\hline AS-20 & 0.12 & 30 & 14 & 0.014 \\
\hline AS-21 & 0.088 & 30 & 17 & 0.014 \\
\hline AS-22 & 0.14 & 25 & 24 & 0.0049 \\
\hline AS-23 & 0.081 & 30 & 14 & 0.019 \\
\hline AS-24 & 0.11 & 27 & 20 & 0.015 \\
\hline AS-25 & 0.083 & 20 & 20 & 0.0097 \\
\hline AS-26 & 0.088 & 21 & 15 & 0.039 \\
\hline AS-27 & 0.083 & 16 & 15 & 0.039 \\
\hline AS-28 & 0.10 & 23 & 10 & 0.029 \\
\hline AS-29 & 0.053 & 26 & 13 & 0.014 \\
\hline AS-30 & 0.061 & 20 & 17 & 0.013 \\
\hline AS-31 & 0.095 & 17 & 14 & 0.047 \\
\hline AS-32 & 0.093 & 24 & 14 & 0.046 \\
\hline AS-33 & 0.092 & 27 & 14 & 0.044 \\
\hline AS-34 & 0.15 & 25 & 20 & 0.053 \\
\hline AS-35 & 0.11 & 28 & 19 & 0.047 \\
\hline AS-36 & 0.39 & 29 & $>40$ & 0.052 \\
\hline AS-37 & 0.24 & $>40$ & 11 & 0.34 \\
\hline AS-38 & 0.13 & 26 & 31 & 0.041 \\
\hline AS-39 & 0.087 & 20 & 16 & 0.013 \\
\hline AS-40 & 0.094 & 21 & 14 & 0.013 \\
\hline AS-41 & 0.059 & 35 & 21 & 0.051 \\
\hline AS-42 & 0.19 & 34 & 19 & 0.048 \\
\hline AS-43 & 0.11 & 21 & 15 & 0.044 \\
\hline AS-52 & 0.26 & 34 & $>40$ & 0.024 \\
\hline AS-53 & 0.11 & $>40$ & $>40$ & 0.057 \\
\hline Bortezomib & 0.039 & 0.75 & $>40$ & 0.0088 \\
\hline
\end{tabular}

Abbreviation: $\mathrm{IC}_{50}$, half maximal inhibitory concentration.

$20 S$ proteasome was prepared from human erythrocytes.

A preliminary study showed that the picolinic amide derivative AS-15 displayed in vivo antitumor activity, and an advanced SAR study based on this compound was performed to unveil the effects of substituents on pyridine nucleus (from AS-18 to AS-43). In most cases except for the hydroxyl-bearing analogues AS-36 and AS-37, compounds of this class exhibited lower $\mathrm{IC}_{50}$ values than the mother compound AS-15. In particular, the 3,6- $\mathrm{Cl}_{2}$ (AS-29), 3-Br (AS-30) and 6-MeO (AS-41) derivatives showed comparable potency to that of bortezomib. In general, good cytotoxicity was observed with the

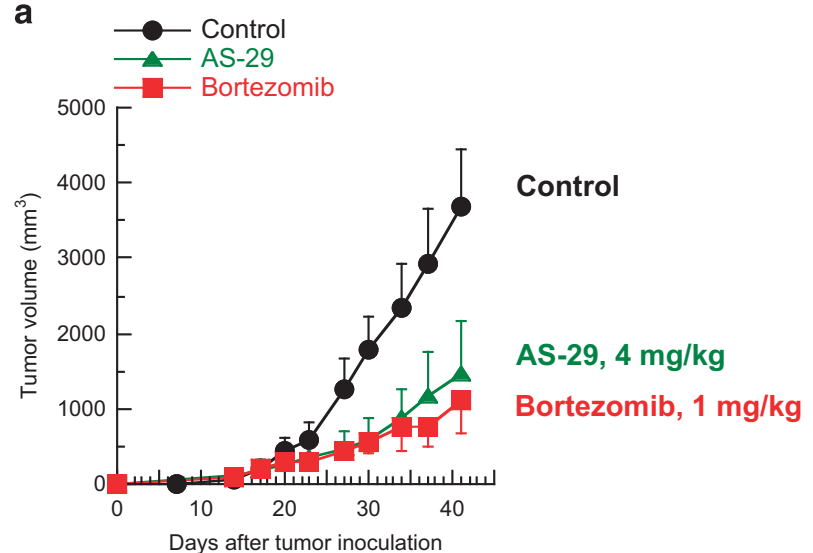

b
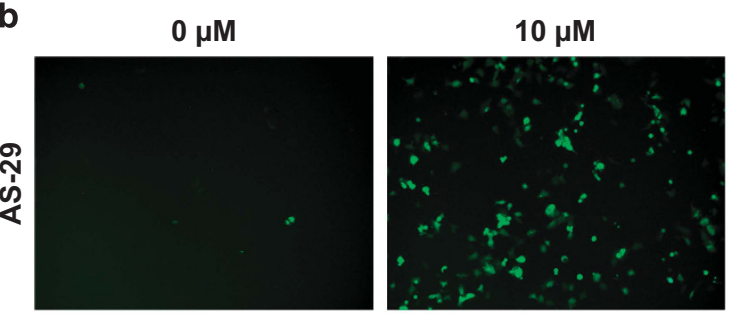

C

$\mathbf{O h}$

$\mathrm{Oh}$

$24 \mathrm{~h}$
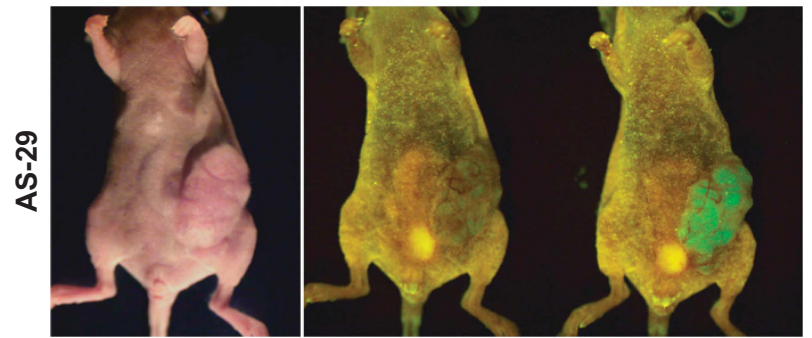

Figure 6 Antitumor activity of AS-29 and in vivo imaging of proteasome inhibition. (a) The antitumor activity on RPMI8226 xenografts. RPMI8226 cells were subcutaneously inoculated into SCID mice on day 0. AS-29 and bortezomib were administered intravenously twice weekly for 4 weeks from day 13. (b) Accumulation of proteasome-sensitive fluorescent proteins by AS-29. HEK293PS cells expressing the proteasome-sensitive fluorescent proteins were incubated with AS-29 for $18 \mathrm{~h}$. (c) In vivo imaging of proteasome inhibition by AS-29. AS-29 was administered intravenously to mice bearing HEK293PS tumors. The tumors were monitored using the in vivo imaging system at $24 \mathrm{~h}$ after administration.

derivatives of this type. Inter alia, the 3-fluoro analogs AS-22 exhibited the most potent cytotoxicity with an $\mathrm{IC}_{50}$ value of $0.0049 \mu \mathrm{m}$. The analogs with the P2 position replaced by glycine AS-52 and alanine AS-53 did not alter the biological activities considerably. Interestingly, inhibitory activity toward the chymotrypsin-like activity of $20 \mathrm{~S}$ proteasome and cytotoxicity have no direct relationship. Thus, because AS-29 had biological activities comparable potency to bortezomib among the tyropeptin-boronic acid derivatives, we investigated the antitumor effects of AS-29 on human multiple myeloma cells.

AS-29 inhibited intracellular proteasome activities and induced significant accumulation of ubiquitinated proteins in human multiple myeloma cells. ${ }^{63}$ The transcription factor NF- $\kappa \mathrm{B}$ controls cell growth and confers a significant survival potential in a variety of tumors. Inhibition of NF- $\kappa \mathrm{B}$ activation by proteasome inhibitors is considered the major mechanism of action of antitumor activity. Therefore, we 
examined the effect of AS-29 on NF- $\mathrm{KB}$ activation in RPMI8226 cells.

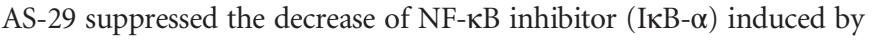
tumor necrosis factor- $\alpha$ and increased $\mathrm{I} \kappa \mathrm{B}-\alpha$ phosphorylation. Furthermore, AS-29 blocked the nuclear translocation of the NF- $\kappa$ B p65 subunit after tumor necrosis factor- $\alpha$ stimulation, and AS-29 inhibited the DNA-binding activity of NF- $\kappa B$ p65. These results indicated that AS-29 inhibits NF- $\kappa$ B activation by stabilizing I $\kappa \mathrm{B}-\alpha$.

Proteasome inhibitors such as bortezomib induce apoptosis through the activation of both extrinsic (caspase-8-mediated) and intrinsic (caspase-9-mediated) apoptotic pathways. ${ }^{64,65}$ AS-29-induced apoptosis is accompanied by the activation of caspase- 8 and -9 . Thus AS-29 triggers two main apoptosis pathways: death receptor pathway and mitochondria pathway. On the other hand, bortezomib is reported to activate the endoplasmic reticulum-resident caspase-12 in multiple myeloma cells. ${ }^{64}$ Therefore, we investigated whether caspase-12 is activated by AS-29 and found that bortezomib activated caspase-12, whereas AS-29 did not.

Genome-wide transcriptional expression analysis is a powerful strategy for characterizing the biological activity of bioactive small molecules, considering that bioactive small molecules having similar mechanisms of action may induce similar gene expression profiles. ${ }^{66-68}$ Genome-wide transcriptional expression analysis using hierarchical clustering showed a positive correlation between genomewide gene expression signatures of AS-29 and bortezomib, suggesting that AS-29 has biological activities similar to those of bortezomib in multiple myeloma cells. The COMPARE analysis using a human cancer cell line, JFCR39, ${ }^{69}$ revealed that the growth inhibition patterns of the tyropeptin-boronic acid derivatives were similar to those of bortezomib but were not identical (Peason's correlation coefficient, 0.706). ${ }^{63}$ In particular, de-dichloro-AS-29 derivative showed a more potent cytotoxicity against human glioblastoma SF-539 cells than bortezomib. Therefore, tyropeptin-boronic acid derivatives might have unique proteasome inhibitors with mechanisms different from those of bortezomib.

Furthermore, the in vivo antitumor activity of AS-29 was investigated using xenograft models of RPMI8226 cells. We found that intravenous administration of AS-29 $\left(4 \mathrm{mg} \mathrm{kg}^{-1}\right)$ twice weekly for 4 weeks significantly suppresses the growth of subcutaneous tumors (Figure 6a). Therefore, AS-29 could be a lead compound in the development of novel next-generation anti-multiple myeloma agents.

\section{PROSPECT}

It was once thought that a pivotal cellular system such as the proteasome could not be a viable molecular target for antitumor drugs. The impressive clinical success of bortezomib treatment, however, demonstrates that the proteasome is a hopeful molecular target for cancer therapy. Bortezomib therapy dramatically improves the outcome in multiple myeloma patients and has become the standard of care for patients with either relapsed/refractory or previously untreated multiple myeloma. However, bortezomib induces many side effects, including painful peripheral neuropathy, orthostatic hypotension, pyrexia, cardiac and pulmonary disorders, adverse gastrointestinal events, myelosuppression and thrombocytopenia asthenia. $^{52,70-72}$ Furthermore, prolonged treatment with bortezomib is associated with development of drug resistance. ${ }^{73}$ These issues emphasize the need for the development of novel proteasome inhibitors. In 2015, an orally available proteasome inhibitor, ixazomib, was approved for use in patients with relapsed/refractory multiple myeloma. ${ }^{74}$ Ixazomib is rapidly hydrolyzed in plasma to its biologically active form, MLN2238. It demonstrated greater activity against multiple myeloma cells than bortezomib in preclinical studies. ${ }^{75}$ Recent attempts to develop next-generation proteasome inhibitors have focused on orally active compounds, such as ixazomib.

Efficient methods to assess antitumor activity are required to develop new orally active proteasome inhibitors. Because the proteasome-inhibitory activity in tumors is highly correlated with antitumor activity in mice, in vivo monitoring of proteasome activity of tumors in mice is a useful technique for estimating antitumor activity. A ubiquitin-luciferase bioluminescence imaging reporter method has been developed to directly assess proteasome activity in tumors of living mice. ${ }^{76}$ The luminescent reporter is a fusion protein containing firefly luciferase and four copies of a mutant ubiquitin G76V that resists cleavage by ubiquitin hydrolases. The reporter is undetectable under steady-state conditions because of rapid degradation by proteasomes. However, it remains stable and intact in the presence of proteasome inhibitors. Therefore, this reporter has been used to assess the performance of proteasome inhibitors in mouse models. ${ }^{77}$ Meanwhile, fluorescent reporters have also been developed to assess proteasome activity in living cells. ${ }^{78,79}$ These fluorescent reporters (for example, green fluorescent protein) allow for real-time imaging of proteasome activity because special reagents (for example, D-luciferin) are not required. In vivo imaging of proteasome activity using fluorescent reporters in living animals, however, had not been reported. Therefore, we developed a system for the in vivo fluorescence imaging of proteasome activity in the tumors of living mice using a proteasome-sensitive fluorescent reporter, ZsProSensor- $1 .^{80}$ This reporter is a fusion protein containing a fluorescent protein, ZsGreen, and mouse ornithine decarboxylase that is degraded by the proteasome without ubiquitin conjugation. ${ }^{81}$ In stably transfected cells expressing ZsProSensor-1, the fluorescent reporter is rapidly degraded under steady-state conditions, whereas it is stabilized in the presence of proteasome inhibitors such as AS-29 and accumulates in the cells (Figure 6b). Subcutaneous inoculation of transfected cells expressing ZsProSensor-1 into nude mice resulted in tumor formation, and AS-29 administered intravenously to the tumorbearing mice induced the accumulation of ZsProSensor-1 protein and emission of the fluorescent signal in the tumors of living mice (Figure 6c). Intravenous administration of bortezomib significantly suppressed tumor growth and increased fluorescent protein in the tumors, while oral administration did not exert antitumor effects and did not induce the accumulation of fluorescent protein in the tumors. ${ }^{80}$ Moreover, oral administration of delanzomib, an orally active proteasome inhibitor, ${ }^{82,83}$ markedly reduced tumor growth and emitted a fluorescent signal in the tumors. Therefore, the use of this in vivo imaging system can easily explore new orally active proteasome inhibitors. We are currently developing orally active tyropeptin-boronic acid derivatives and have already obtained several promising candidates. Our future reports will provide more details.

\section{CONFLICT OF INTEREST}

The authors declare no conflict of interest.

\section{ACKNOWLEDGEMENTS}

We thank all our colleagues, many of whom we cannot list in this limited space. We extend special thanks to Professor M Shibasaki, Drs D Ikeda, H Iinuma, Y Umezawa and M Kawada for helpful discussions; Drs R Sekizawa, M Iijima, Y Yamazaki and D Tatsuda for the biological studies; Drs S Hirosawa, R Sawa, M Abe and H Abe for the chemical studies; Drs H Hashizume and M Igarashi for the microbiological studies; and T Masuda and S Ohba for the animal experiments. 
1 Tanaka, K., Mizushima, T. \& Saeki, Y. The proteasome: molecular machinery and pathophysiological roles. Biol. Chem. 393, 217-234 (2012).

2 Hershko, A. \& Ciechanover, A. The ubiquitin system. Annu. Rev. Biochem. 67 425-479 (1998).

3 Ravid, T. \& Hochstrasser, M. Diversity of degradation signals in the ubiquitinproteasome system. Nat. Rev. Mol. Cell Biol. 9, 679-U625 (2008).

4 Coux, O., Tanaka, K. \& Goldberg, A. L. Structure and functions of the $20 \mathrm{~S}$ and 26S proteasomes. Annu. Rev. Biochem. 65, 801-847 (1996).

5 Baumeister, W., Walz, J., Zuhl, F. \& Seemuller, E. The proteasome: paradigm of a selfcompartmentalizing protease. Cell 92, 367-380 (1998).

6 DeMartino, G. N. \& Gillette, T. G. Proteasomes: machines for all reasons. Cell 129, 659-662 (2007).

7 Groll, M. \& Huber, R. Inhibitors of the eukaryotic 20 S proteasome core particle: a structural approach. Biochim. Biophys. Acta 1695, 33-44 (2004).

8 Maki, C. G. \& Howley, P. M. Ubiquitination of p53 and p21 is differentially affected by ionizing and UV radiation. Mol. Cell. Biol. 17, 355-363 (1997).

9 Pagano, M. et al. Role of the ubiquitin-proteasome pathway in regulating abundance of the cyclin-dependent kinase inhibitor p27. Science 269, 682-685 (1995).

10 Ciechanover, A. et al. Degradation of nuclear oncoproteins by the ubiquitin system in vitro. Proc. Natl Acad. Sci. USA 88, 139-143 (1991).

11 Palombella, V. J., Rando, O. J., Goldberg, A. L. \& Maniatis, T. The ubiquitin-proteasome pathway is required for processing the NF-kappa B1 precursor protein and the activation of NF-kappa B. Cell 78, 773-785 (1994).

12 Rentsch, A. et al. Synthesis and pharmacology of proteasome inhibitors. Angew. Chem Int. Ed. 52, 5450-5488 (2013).

13 Kisselev, A. F., van der Linden, W. A. \& Overkleeft, H. S. Proteasome inhibitors an expanding army attacking a unique target. Chem. Biol. 19, 99-115 (2012).

14 Crawford, L. J., Walker, B. \& Irvine, A. E. Proteasome inhibitors in cancer therapy. J. Cell Commun. Signal. 5, 101-110 (2011).

15 Kubiczkova, L., Pour, L., Sedlarikova, L., Hajek, R. \& Sevcikova, S. Proteasome inhibitors - molecular basis and current perspectives in multiple myeloma. J. Cell. Mol. Med. 18, 947-961 (2014)

16 Momose, I. \& Kawada, M. The therapeutic potential of microbial proteasome inhibitors Int. Immunopharmacol. 37, 23-30 (2016).

17 Lee, A. H., Iwakoshi, N. N., Anderson, K. C. \& Glimcher, L. H. Proteasome inhibitors disrupt the unfolded protein response in myeloma cells. Proc. Natl Acad. Sci. USA 100, 9946-9951 (2003).

18 Fribley, A., Zeng, Q. \& Wang, C. Y. Proteasome inhibitor PS-341 induces apoptosis through induction of endoplasmic reticulum stress-reactive oxygen species in head and neck squamous cell carcinoma cells. Mol. Cell. Biol. 24, 9695-9704 (2004).

19 Adams, J. The development of proteasome inhibitors as anticancer drugs. Cancer Cel/ 5 417-421 (2004).

20 Adams, J. The proteasome: a suitable antineoplastic target. Nat. Rev. Cancer 4 349-360 (2004)

21 Omura, S. et al. Lactacystin, a novel microbial metabolite, induces neuritogenesis of neuroblastoma-cells. J. Antibiot. 44, 113-116 (1991).

22 Omura, S. et al. Structure of lactacystin, a new microbial metabolite which induces differentiation of neuroblastoma-cells. J. Antibiot. 44, 117-118 (1991).

23 Fenteany, G. et al. Inhibition of proteasome activities and subunit-specific aminoterminal threonine modification by lactacystin. Science 268, 726-731 (1995).

24 Dick, L. R. et al. Mechanistic studies on the inactivation of the proteasome by lactacystin A central role for clasto-lactacystin beta-lactone. J. Biol. Chem. 271, 7273-7276 (1996).

25 Dick, L. R. et al. Mechanistic studies on the inactivation of the proteasome by lactacystin in cultured cells. J. Biol. Chem. 272, 182-188 (1997).

26 Corey, E. J. \& Li, W. D. Z. Total synthesis and biological activity of lactacystin, omuralide and analogs. Chem. Pharm. Bull 47, 1-10 (1999)

27 Umezawa, H. Enzyme Inhibitors of Microbial Origin (University of Tokyo Press, Tokyo, Japan, 1972).

28 Aoyagi, T. Biochemistry of Peptide Antibiotics (Walter de Gruyter, Berlin, Germany, 1990).

29 Momose, I. et al. Tyropeptins A and B, new proteasome inhibitors produced by Kitasatospora sp. MK993-dF2. I. Taxonomy, isolation, physico-chemical properties and biological activities. J. Antibiot. 54, 997-1003 (2001).

30 Omura, S., Takahashi, Y., Iwai, Y. \& Tanaka, H. Kitasatosporia, a new genus of the order Actinomycetales. J. Antibiot. 35, 1013-1019 (1982).

31 Zhang, Z. S., Wang, Y. \& Ruan, J. S. A proposal to revive the genus Kitasatospora (Omura, Takahashi, Iwai, and Tanaka 1982). Int. J. Syst. Bacteriol. 47, 1048-1054 (1997).

32 Ichikawa, N. et al. Genome sequence of Kitasatospora setae NBRC 14216': an evolutionary snapshot of the family Streptomycetaceae. DNA Res. 17, 393-406 (2010).

33 Momose, I. et al. Tyropeptins A and B, new proteasome inhibitors produced by Kitasatospora sp MK993-dF2-II. Structure determination and synthesis. J. Antibiot. 54, 1004-1012 (2001).

34 Rydon, H. N. \& Smith, P. W. G. A new method for the detection of peptides and similar compounds on paper chromatograms. Nature 169, 922-923 (1952).

35 Tsubuki, S. et al. Purification and characterization of a Z-Leu-Leu-Leu-MCA degrading protease expected to regulate neurite formation: a novel catalytic activity in proteasome. Biochem. Biophys. Res. Commun. 196, 1195-1201 (1993)

36 Momose, I., Sekizawa, R., linuma, H. \& Takeuchi, T. Inhibition of proteasome activity by tyropeptin A in PC12 cells. Biosci. Biotechnol. Biochem. 66, 2256-2258 (2002).
37 Obin, M. et al. Neurite outgrowth in PC12 cells-distinguishing the roles of ubiquitylation and ubiquitin-dependent proteolysis. J. Biol. Chem. 274, 11789-11795 (1999).

38 Unno, M. et al. Structure determination of the constitutive $20 \mathrm{~S}$ proteasome from bovine liver at 2.75 angstrom resolution. J. Biochem. 131, 171-173 (2002).

39 Unno, M. et al. The structure of the mammalian $20 \mathrm{~S}$ proteasome at 2.75 angstrom resolution. Structure 10, 609-618 (2002).

40 Groll, M. et al. Structure of $20 \mathrm{~S}$ proteasome from yeast at 2.4 angstrom resolution. Nature 386, 463-471 (1997).

41 Huber, E. M. et al. Immuno- and constitutive proteasome crystal structures reveal differences in substrate and inhibitor specificity. Cell 148, 727-738 (2012).

42 Momose, I., Umezawa, Y., Hirosawa, S., linuma, H. \& Ikeda, D. Structure-based design of derivatives of tyropeptin A as the potent and selective inhibitors of mammalian $20 \mathrm{~S}$ proteasome. Bioorg. Med. Chem. Lett. 15, 1867-1871 (2005).

43 Momose, I. et al. Synthesis and activity of tyropeptin A derivatives as potent and selective inhibitors of mammalian 20S proteasome. Biosci. Biotechnol. Biochem. 69, 1733-1742 (2005)

44 Momose, I., lijima, M., Kawada, M. \& Ikeda, D. A new proteasome inhibitor, TP-110, induces apoptosis in human prostate cancer PC-3 cells. Biosci. Biotechnol. Biochem. 71, 1036-1043 (2007).

45 lijima, M., Momose, I. \& Ikeda, D. TP-110, a new proteasome inhibitor, down-regulates IAPs in human multiple myeloma cells. Anticancer Res. 29, 977-985 (2009).

46 lijima, M., Momose, I. \& Ikeda, D. Increased ABCB1 expression in TP-110-resistant RPMI-8226 cells. Biosci. Biotechnol. Biochem. 74, 1913-1919 (2010).

47 Adams, J. et al. Potent and selective inhibitors of the proteasome: dipeptidy boronic acids. Bioorg. Med. Chem. Lett. 8, 333-338 (1998).

48 Adams, J. et al. Proteasome inhibitors: a novel class of potent and effective antitumor agents. Cancer Res. 59, 2615-2622 (1999).

49 Meister, S. et al. Extensive immunoglobulin production sensitizes myeloma cells for proteasome inhibition. Cancer Res. 67, 1783-1792 (2007).

50 Obeng, E. A. et al. Proteasome inhibitors induce a terminal unfolded protein response in multiple myeloma cells. Blood 107, 4907-4916 (2006).

51 Orlowski, R. Z. et al. Phase I trial of the proteasome inhibitor PS-341 in patients with refractory hematologic malignancies. J. Clin. Oncol. 20, 4420-4427 (2002).

52 Richardson, P. G. et al. A phase 2 study of bortezomib in relapsed, refractory myeloma. N. Engl. J. Med. 348, 2609-2617 (2003).

53 Jagannath, S. et al. A phase 2 study of two doses of bortezomib in relapsed or refractory myeloma. Br. J. Haematol. 127, 165-172 (2004).

54 Richardson, P. G. et al. Bortezomib or high-dose dexamethasone for relapsed multiple myeloma. N. Engl. J. Med. 352, 2487-2498 (2005).

55 Kane, R. C., Bross, P. F., Farrell, A. T. \& Pazdur, R. Velcade: U.S. FDA approval for the treatment of multiple myeloma progressing on prior therapy. Oncologist $\mathbf{8}, 508-513$ (2003).

56 Kane, R. C., Farrell, A. T., Sridhara, R. \& Pazdur, R. United States Food and Drug Administration approval summary: bortezomib for the treatment of progressive multiple myeloma after one prior therapy. Clin. Cancer Res. 12, 2955-2960 (2006).

57 Richardson, P. G. et al. Bortezomib in the front-line treatment of multiple myeloma. Expert Rev. Anticancer Ther. 8, 1053-1072 (2008).

58 Kane, R. C. et al. Bortezomib for the treatment of mantle cell lymphoma. Clin. Cancer Res. 13, 5291-5294 (2007).

59 Matteson, D. S., Sadhu, K. M. \& Lienhard, G. E. (R)-1-Acetamido-2-phenylethaneboronic acid. A specific transition-state analog for chymotrypsin. J. Am. Chem. Soc. 103, 5241-5242 (1981).

60 Kettner, C. A. \& Shenvi, A. B. Inhibition of the serine proteases leukocyte elastase, pancreatic elastase, cathepsin G, and chymotrypsin by peptide boronic acids. J. Biol. Chem. 259, 5106-5114 (1984).

61 Watanabe, T. et al. Synthesis of boronic acid derivatives of tyropeptin: proteasome inhibitors. Bioorg. Med. Chem. Lett. 19, 2343-2345 (2009).

62 Watanabe, T. et al. Structure-activity relationship of boronic acid derivatives of tyropeptin: proteasome inhibitors. Bioorg. Med. Chem. Lett. 20, 5839-5842 (2010).

63 Momose, I. et al. Antitumor effects of tyropeptin-boronic acid derivatives: new proteasome inhibitors. Cancer Sci. 105, 1609-1615 (2014).

64 Landowski, T. H., Megli, C. J., Nullmeyer, K. D., Lynch, R. M. \& Dorr, R. T. Mitochondrial-mediated disregulation of $\mathrm{Ca}^{2+}$ is a critical determinant of Velcade (PS-341/Bortezomib) cytotoxicity in myeloma cell lines. Cancer Res. 65, 3828-3836 (2005).

65 Mitsiades, N. et al. Molecular sequelae of proteasome inhibition in human multiple myeloma cells. Proc. Natl Acad. Sci. USA 99, 14374-14379 (2002).

66 Hieronymus, H. et al. Gene expression signature-based chemical genomic prediction identifies a novel class of HSP90 pathway modulators. Cancer Cell 10, 321-330 (2006).

67 Lamb, J. et al. The connectivity map: Using gene-expression signatures to connect small molecules, genes, and disease. Science 313, 1929-1935 (2006).

68 Wei, G. et al. Gene expression-based chemical genomics identifies rapamycin as a modulator of MCL1 and glucocorticoid resistance. Cancer Cell 10, 331-342 (2006).

69 Yamori, T. et al. Potent antitumor activity of MS-247, a novel DNA minor groove binder, evaluated by an in vitro and in vivo human cancer cell line panel. Cancer Res. 59, 4042-4049 (1999).

70 Richardson, P. G. et al. Frequency, characteristics, and reversibility of peripheral neuropathy during treatment of advanced multiple myeloma with bortezomib. J. Clin. Oncol. 24, 3113-3120 (2006).

71 Lonial, S. et al. Risk factors and kinetics of thrombocytopenia associated with bortezomib for relapsed, refractory multiple myeloma. Blood 106, 3777-3784 (2005). 
72 Ludwig, H., Khayat, D., Giaccone, G. \& Facon, T. Proteasome inhibition and its clinical prospects in the treatment of hematologic and solid malignancies. Cancer 104, 1794-1807 (2005).

73 Ruschak, A. M., Slassi, M., Kay, L. E. \& Schimmer, A. D. Novel proteasome inhibitors to overcome bortezomib resistance. J. Natl. Cancer Inst. 103, 1007-1017 (2011).

74 Kupperman, E. et al. Evaluation of the proteasome inhibitor MLN9708 in preclinical models of human cancer. Cancer Res. 70, 1970-1980 (2010).

75 Chauhan, D. et al. In vitro and in vivo selective anti tumor activity of a novel orally bioavailable proteasome inhibitor MLN9708 against multiple myeloma cells. Clin. Cancer Res. 17, 5311-5321 (2011).

76 Luker, G. D., Pica, C. M., Song, J. L., Luker, K. E. \& Piwnica-Worms, D. Imaging 26S proteasome activity and inhibition in living mice. Nat. Med. 9, 969-973 (2003).

77 Williamson, M. J. et al. Comparison of biochemical and biological effects of ML858 (salinosporamide A) and bortezomib. Mol. Cancer Ther. 5, 3052-3061 (2006).
78 Dantuma, N. P., Lindsten, K., Glas, R., Jellne, M. \& Masucci, M. G. Short-lived green fluorescent proteins for quantifying ubiquitin/proteasome-dependent proteolysis in living cells. Nat. Biotechnol. 18, 538-543 (2000).

79 Rickardson, L., Wickstrom, M., Larsson, R. \& Lovborg, H. Image-based screening for the identification of novel proteasome inhibitors. J. Biomol. Screen. 12, 203-210 (2007).

80 Momose, I. et al. In vivo imaging of proteasome inhibition using a proteasome-sensitive fluorescent reporter. Cancer Sci. 103, 1730-1736 (2012).

81 Murakami, Y. et al. Ornithine decarboxylase is degraded by the $26 \mathrm{~S}$ proteasome without ubiquitination. Nature 360, 597-599 (1992).

82 Dorsey, B. D. et al. Discovery of a potent, selective, and orally active proteasome inhibitor for the treatment of cancer. J. Med. Chem. 51, 1068-1072 (2008).

83 Piva, R. et al. CEP-18770: a novel, orally active proteasome inhibitor with a tumor-selective pharmacologic profile competitive with bortezomib. Blood 111, 2765-2775 (2008). 